\title{
Futures literacy in the loop
}

\author{
Jan Erik KARLSEN* (1)
}

\begin{abstract}
This article proposes a functional historicist explanation to explicate the core ideas and underlying logic embedded in the futures literacy concept.

Futures literacy assumes a capacity to reflect on the past, sense and make sense of the present and use this reflective body of knowledge when anticipating the future.

Arguably, futures literacy must be learned, sustained, and regained; it requires a continuous, anticipative, and recursive loop. Recursivity, where an effect in an initial period acts as a cause in the next period, retroacts between the future and present, regaining anticipation. Anticipation has causal effects in the way it structures our images of the future and the avenue we follow when striving to achieve this image. Such a causal structure implies both feedforward and feedback control and is contained in the logic of functional explanations used in sociology.
\end{abstract}

Keywords: Futures literacy, Time concepts, Functional models, Recursivity

\section{Background}

\section{The future is open but not empty}

All our decisions, whether taken by an individual, an organization or a society concern the future. However, most decisions are based on experiences of the past and the present. Futures literacy [1] adds something besides experiences to the premises of decision-making by including anticipation and images of futures. Such an awareness demonstrated both in the foresight literature and in Unesco's success at establishing a Global futures Literacy network (https://en.unesco.org/futuresliteracy/ about), may be linked to the idea of the Greek triangle, initially introduced in futures studies by Michel Godet [2, 3]. Godet puts forward the idea that a strategic culture of a collective actor can be anchored in a Greek triangle. He sees prospective strategy as a decision tool that links anticipation to action through appropriation. The pillars of the Greek triangle are reciprocally interlinked: Anticipation is both the awareness of the future and prospective thought. Appropriation is joint commitment, collective mobilization and sharing of values. Action is strategic resolve and planning.

*Correspondence: jan.e.karlsen@uis.no

University of Stavanger Business School, N-4036 Stavanger, Norway
The triangle helps a decision-maker discern the plausible futures and develop a strategy accordingly. However, in its complete format, it requires prospective and creative idea development, collective mobilization, and awareness, and understanding of the ideas, as well as a willingness to take strategic or decisive action.

Foresight studies emphasize all activities that spring from the Greek triangle and that are definitively considered equal and necessary elements in mainstream foresight methodology. These activities can be chronological and one-off linear elements, first think, then discuss and finally implement measures to realize the future images. Likewise, they can be overlapping and recurring since thinking, debating, and implementing can take place as activities parallel in time. Besides, and more importantly they can be circular and recurring activities. When we have thought, debated, and implemented measures, we return to novel, collective thought and debate processes before we move into shaping another future landscape.

Even if we follow the logic of the Greek triangle, there is no guarantee of success in creating our desired future. But we can try. Our mental powers and imagination are tested when we form and seek to bring about different images of the future. Our ability to discuss, listen and share our views, whether we are specialists or laypeople, 
is sharpened when we need to determine what future images we want to realize, and our capability is pushed to the limit if we really want to realize the future we prefer.

This article assumes that futures literacy is what you obtain when all three pillars of the Greek triangle are activated. Subsequently, futures literacy is a phenomenon that continuously renews itself in an ever-recurring loop.

\section{The concept of literacy}

Gone are the days when literacy just meant proficiency in reading, writing and arithmetic. Progress and digital technologies have transformed what it means to be literate and to experience literacy. Today there are numerous types of literacy [4], helping us navigate life and engage in societal activities. The definition of literacy has stretched to encompass new ways of meaning-making, which are sometimes connected to functions linking literacy to purposes and sometimes to the competence level needed for problem-solving. UNESCO (2006, p. 147) remarks:

At first glance, 'literacy' would seem to be a term that everyone understands. But at the same time, literacy as a concept has proved to be both complex and dynamic, continuing to be interpreted and defined in a multiplicity of ways. People's notions of what it means to be literate, or illiterate are influenced by academic research, institutional agendas, national context, cultural values and personal experiences.

Literacy is plural, being practised in specific contexts for dedicated purposes and using specific languages. Each kind of literacy emerges from a dedicated teaching and learning endeavour. Literacy is produced; it does not simply materialize. It involves a continuum of learning that is measured at diverse skill levels. Arguably, literacy in terms of proficiency levels has no upper limit and must be upheld in people and institutions to be sustained. Therefore, literacies call for assessment of something that is tangible, and assessments require criteria, procedures, and instruments. An assessment applying criteria of conceptual goodness, e.g., as spelled out by Gerring [5] to explore the characteristics and the concept validity of futures literacy, is much needed, however still pending. This raises the question of whether futures literacy is tangible and whether it will ever be possible to assess other than as a primitive scientific term.

\section{Futures literacy - the mastery of the unmade To be, or not to be, a futures literate}

Theoretically, it is quite challenging to conduct research on the future - on something that has not yet been created or has not yet materialized. Mainstream scientific inquiry is linked to evidence; we provide evidence for our claims and assumptions. And all our scientific evidence is linked to the past. We cannot prove anything about the future because it has not yet materialized. Therefore, it does not meet the most important criterion in science - the requirement of falsifiability. The future cannot be falsified, nor can it be verified. For when our imagined future has become the present, it is no longer the future, but the present, and it immediately becomes the past. Futures exist in our thoughts, but they do not materialize in the temporal realm we deem the future. Still, we assume that any present contains the emergence of a possible future [6]. This future might not be the most plausible or the most preferred one; still, it is a future.

Miller [7-10] labels a novel kind of literal mastery 'futures literacy' (FL). According to Miller [1], FL is a cumulative capacity or competence to explore the potential of the present to give rise to the future, and he deems FL 'a capability'. It is the skill that allows people to better understand the role that the future plays in what they see and do' (p. 294). This kind of skill is produced via a threestage learning cycle (revealing, reframing, rethinking) performed in a particular work process labelled Futures Literacy Laboratory (FLL). However, the purpose of FL is to produce decisions to enact a preferred future. Miller argues that this is best done by engaging in the FFL processes.

The FL held by a futures literate person is not the result of arbitrary daydreaming. FL involves images of futures produced by targeted learning processes in the FLL and enthused by structured stimulus of anticipation. By contrast, a futures illiterate actor is stuck in the literacy of the past and of the contemporary society even though they do

... deploy anticipatory systems and practices in order to make decisions. For the most part, these decisionmakers engage in anticipatory activities without an explicit awareness of the theory and practice of thinking about the future. In other words, they are futures illiterate ... ([1], p. 8)

Such illiterate actors or communities of practice do not draw on the liberating potential of anticipation. The anticipatory capability underpinning FL must be acquired through active individual and/or organizational learning.

\section{Ontological and epistemological oxymorons}

FL inherits a double set of conceptual challenges - first, to the ambiguous concept of literacy as mentioned above, and second, to the contested concept of the future. The future has neither an ontological nor an epistemological underpinning. The future as such does not exist. Hence, it is difficult to claim that we can learn something and develop a proficiency about something that does not 
exist. And for what purpose? However, that is exactly what Miller [1] proposes. He argues that our imagination about the future, promoted by our anticipation, creates images in the present that predispose our collective actions to a preferred future.

Ontology (the theory of the conceptions of reality) provides criteria for distinguishing between various types of objects and their perceived relationships. Objects can be concrete or abstract, existent, or non-existent, real, or ideal, and their ties can be relations, dependences, or predications. Adam [11] launches the notion of 'immaterial real', by which she means that even though the futures produced (e.g., as images and stories) and traded (e.g., as promises or expectations) do not exist at this time, the process of their creation (e.g., a particular pathway) grants them semi-ontological status. Selin [12] claims that this indicates a way to overcome the problem of realism in the study of the future: 'the future is real in so far as the things, deeds, and words today are locked in on creating particular futures'. Selin's 'sociology of the future' encompasses a fascination with the future tense and how the future - as temporal abstraction, as story, as discursive strategy - is a component of social reality. The 'future holds all the mystery of lore', while the past, which has been colonized, and the present, which is fleeting, do not intrigue her.

Arguably, as a mental object, the future is abstract, non-existent, and ideal. The link to the future may be relational, dependent, and predictive. So, when we deal with a future, we have to ask a basic question: what is there, or what will be there? How do we know that a possible future is or will be? And how do we know the characteristics of the future itself, if it does not exist? If 'future' just refers to a collection of mental events experienced by a person, how do we recognize its very being, its entities and the relations between its entities? Furthermore, how can we make a catalogue of elements that will constitute the future in some specific domain - for example, in a particular organization within an industrial sector? The answer is that we most often revert to some basic ontological assumptions about the future, such as that the future reflects human imagination or a projection of today's situation [13].

Next, how do we establish knowledge of the future that is, statements that are both supposed to be true and believed - thus providing a firm epistemic ground for our justified true beliefs? What is measurable? The future is not testable or falsifiable, but is it measurable or do we have to distinguish knowledge about the past and present from knowledge about future events? Can our ideas, thoughts and actions that are locked in on creating futures serve as proxies of the core ontology of planned change? If future is just thinkable and imaginable, what will serve as true knowledge justifying the epistemic stance - everyone's ideas or the ideas of the experts?

Knowledge implies belief, and foresights frequently require some (often strongly normative) belief about a future state. March [14] argues that beliefs about the future, like beliefs about the past, are the instruments we need to live in the present. However, predictions about the future are often wrong. Imagining and predicting organizations' futures are variations on a fantasy theme - 'reliably incorrect and usefully seductive.' Nevertheless, it is necessary to stimulate our imagination about the roles and functions organizations will have in future societies. Our inclination for rational reasoning and controlled imagination has never obliterated our ability to create beautiful or ugly images of the future. March [14] concludes by saying that the occasional discussion occurring between those who imagine individual organizations as changing and persistent and those who imagine them as rigid, and disposable is an argument not only about truth but also about the beauty and fairness of possible fantasies of human existence and is thus worth taking seriously.

It is not the future as such that is the core of FL. It is the ideas, discussions and deliberations, and the subsequent decisions targeting the futures that matter. FL - if it is to be deemed a proficiency - must be measurable. It must be possible to describe both the ontological and the epistemological aspects of FL. According to Miller [1], FL must be produced in a particular way and in a dedicated Futures Literacy Laboratory to qualify as embodying a sufficient level of literacy regarding the future. That is a tall order. Arguably, futures literacy as a cumulative capacity may be developed in most foresight exercises and workshops.

The future is not transparent and lucid; if it was, arguably the meaning of life would wither, and science would fade away. To think about the future is a most stimulating intellectual exercise that also helps us understand the present more accurately. We may even say that this is the most valuable contribution of foresight exercises that is relevant to the understanding of change processes.

This is what we observe and comprehend: the future as such and futures literacy are oxymorons. They are so different as to have no opportunity to unite. It serves no purpose to try to establish an epistemic stance for something that does not have a unique ontological basis. FL is no true representation of the future. It is just a representation of our imagined images of the future, but it is nevertheless useful in foresight analysis.

So, how do we know that FL is a real proficiency in ways of knowing the later-than-now? And what mechanisms maintain and sustain FL over time, thus ensuring that FL is no one-off event? 


\section{Time, learning and measurement}

Learning any kind of literacy takes time. The time concept represents a fundamental challenge in philosophy because our thoughts about the social world and time reside inside time itself. Arguably, hardly anything exists outside time. As foresight mostly deals with the temporal realm called 'future', it is vital to establish a kind of consensus within which foresight management can operate. In foresights, the time concept is reconstructed. Often, we divide the time span of the future into short, medium and long-term perspectives - short being 5-10 years, medium 10-20 and long-term 20 years and beyond. This time perspective is clearly socially constructed, but for what purpose? A plausible explanation of the conventional use of time horizons in foresights may be found in the purpose of the foresight itself. Because most foresights have a clear action orientation, they need a trustworthy timeframe that does not stretch into eternity but rather is limited to a few decades - a generation or so.

Implicitly, most foresights apply an operational definition of time, not strictly linear, but still a chronological concept. Karlsen et al. [13] claim:

The past is seen as something which has ended, having no starting point but bordering the present, which in turn is defined as the state we experience now and actually live in. Now is consequently something which is there all the time, pushing the future to a state which is not actually here, other than in our minds.

The future is constantly approaching us, but it is reconstructed in recognizable time horizons as applied in foresights. This reconstruction does not change the ontological characteristics of the future; it just makes it easier for us to deem time as an embedded aspect of the changes we imagine when undertaking the practice of foresight. Nordlund [15] surveyed how well-known futurists considered timescales in their central works. Like Karlsen et al. [13] on foresights, Nordlund [15] concludes that 'the time-scale has not been given special attention', other than when specifying scale terms, like short, medium, and long in futures research and forecasting. Thus, these fields do not have a theory of time. Instead, they conceive of time as a rather loose and boundary condition.

According to Miller [1], futures literacy is what is learned and explicated via a particular learning platform - the Futures Literacy Laboratory. This kind of definitional constraint is tricky. Arguably, the process of learning FL is as important as its outcomes. During the laboratory learning process, participants are stimulated to activate various anticipative and cognitive discourse functions through the implementation of various activities and foresight tools. However, it is difficult to monitor
FL learning processes because the variables and contextual factors are numerous. In addition, non-cognitive outcomes such as attitudes and behaviour (e.g., plans and decisions) are hard to ascertain.

Theories of learning, like theories of literacy, have been broadened to shift focus away from the individual mind and towards more social and collective practices. The collective learning processes in FLL resemble what Rogoff et al. [16] deem 'intent participation', which involves a collaborative, horizontal work group structure. In intent participation, experienced futures project leaders facilitate learners' roles and often participate alongside them.

Ideally, any concept - including FL - should provide concise labelling and denote some degree of classification and categorisation of its characteristics and content. FL has no specific indicators or scale and thus is not assessable in a strict sense. Thus, FL is a primitive concept in scientific terms, and any image of the future that meets the requirements of the Greek triangle should qualify as futures literacy, not exclusively images produced in the FLL as argued by Miller [1].

\section{Feedforward and feedback causation}

Arguably, FL contains a double set of causal logics backward and forward causation. For example, when we observe that young people use their mobile phones for a new function or a new purpose, such as when they started taking selfies a decade ago, we know that these events are effects. Other events and acts that happen around us are also effects. We do not see their causes. Often, we do not seek their causes either, but if we do, we do it after the event has emerged. We deduce the process of causation; it is retrospective and imagined. We go backwards in time from the effect to the cause using logical inference. Then we assume that the cause came prior in time to its consequence. Later, when we observe the same or a similar phenomenon, we assume it has the same cause as we initially inferred (unless new causal explanations have turned up). This kind of reasoning falls into the fallacy of infinite regress: each cause is the effect of a previous cause in any case of backward causation.

Backward causation is an important tool in science. So is forward causation, which is the model applied in experiments. In cases of forward causation, all factors but one, which is assumed to have effects or consequences, are excluded to observe an expected outcome. By using the randomly controlled trial (RCT) as an experimental design and repeating the number of trials, this forward causation is tested and possibly verified. So, the forward causation of an experiment is like a prediction with a high degree of certainty.

When thinking about the future (as in FL learning), the causation works both ways and yet somewhat differently. 
Learning FL is more like a mental journey in time. Suddendorf and Corballis $[17,18]$ describe this as 'time travel in the head', which includes the ability to intellectually project ourselves backwards to relive, or forwards to preexperience, events. They claim that past and future journeys share phenomenological features and activate equal parts of the brain. They also suggest that because humans have proven to be extremely adept at contemplating, planning, and shaping the future, and because they cannot identify similar characteristics in non-human beings, humans are most likely the only creatures capable of effective mental time travel, including travelling into the future.

The future is not fully predictable, yet it is the result of complex interactions. Therefore, FL is best seen as a kind of temporal (fantasy-driven) or uncertain reflexivity in which meaning is reconstructed from an interpreted feedback process $[19,20]$ or even from some form of time-stretching [21]. Cunha [22] suggests that invented futures are the result of this switching between multiple time horizons - lessons from history, current opportunities, and future visions. Such time horizons are not easy to distinguish and characterize.

Futures literacy builds, by means of anticipation, a condition in the future that runs backwards to the present to ensure that the condition is met. In such a manner, anticipation has future effects; it has forward causation. The anticipated FL (as a cause) is observed, while the effect (the future outcome) is just assumed. However, these effects are not observed in the future but in the present because the future as such cannot be observed. Anticipating the future is thus different from the experimental observation and verification of both cause and effect. Either we consider the past (and its deduced causes) or the future (and its assumed effects), and we move forward in linear time.

The infinite loop created by the three FLL learning steps [1] and the commitments of succeeding generations gives this reciprocal causal structure its distinctive features. The model contains both a feedforward and a feedback process. Louie [23] argues in his analysis of Rosen's $(1985,2003,2012)$ anticipatory systems, that 'anticipatory behaviour involves the concept of feedforward [...], rather than feedback. This means that feedback control is error-actuated, while feedforward behaviour is pre-set by an anticipated future state. Both feedforward and feedback ideas comply with the classical notion that a cause must precede its effect and that this has a linear time assumption.

\section{FL as self-fulfilling prophecy}

FL may be considered a self-fulfilling prophecy (Thomas, 1923; Thomas and Swain, 1928; Mead, 1936 [24];, 1967).
If change agents go into a change process and expect resistance, they will find it. The past is thus frozen solid and prevents the future from being significantly different from the present. Self-referential foresights follow an opposite logic. Here, the future is frozen in a pattern that is expected or expected to be avoided. Expectation is a subjective notion of the future. Before a change occurs, there is an expectation of the change. Expecting a loss or failure and doing little or nothing to prevent it increases the likelihood that the expected outcome will occur.

An illustration of this phenomenon could be observed in Greece in the summer of 2015. The banks were closed for several weeks, regular banking operations were suspended, and Greek citizens were only allowed to withdraw 60 euros a day from cashpoint machines. In response, that was exactly what the Greeks did. The exception was the pensioners whose pensions were paid through the banks. Long queues in front of the cashpoint machines could be observed in Athens daily. The machines were being emptied because the banks did not receive a supply of euros. Bankruptcies were avoided after a public cry of distress, but the prices of bank shares fell to an unprecedented low once the stock exchange could record prices and turnover again.

The perception of a situation leads to behaviours that are either reinforcing or debilitating, and thus the foresight is maintained or undermined. A self-reinforcing behaviour requires an increasingly 'correct' experience of reality, while a self-weakening behaviour creates a more distorted picture of the socially created reality. The gap between initial cognition and expectation decreases or widens, respectively. Thus, the perception of the situation is a key factor in the initiation of self-referential processes because of forethought.

The collective consequences that can arise because of hasty or incorrect situational understandings can be both undesirable and unintended. In any case, these consequences will determine the future of the actor or the organization if they fail to correct the course leading to the outcome of the self-referential foretelling.

The logical structure of self-fulfilling prophecies can be found in functional explanations of social selection processes ([25], p.85). Some social structures create action and thought patterns that reinforce both themselves and the structure they come from. A prediction leads to a behaviour that in turn leads to the prediction coming true, which would not have happened if the prediction had not been made. A statement about a preferred future increases the possibility that, by means of dedicated decisions and actions, this future will become true. The expectation creates actions that lead to the anticipated result. The self-fulfilling prophecy is an active and necessary anticipatory precondition for the prophecy to be 
fulfilled. Because we expect something to happen, we act in a way that makes it probable that it will happen - and thus it happens.

\section{Recursivity and functional explanations A formal representation of futures literacy}

Futures literacy is always produced in the present, but it never has a definitive content. Even though the check question is always the same - 'what is future knowledge?' - changes respond with any futures literacy gathering in the present. Therefore, there is, assumedly, a past FL and a present FL that both influence decisions along the linear timeline. Both may be denoted with 'FL', although they succeed each other. FL is thus to be found on the linear timeline at the same time as it is recreated as a form but with a continually novel content. It runs in a kind of perpetual loop.

Thus, FL has no ending point, it is assumed to be repeating itself at ever more sophisticated levels. If there is to be some criterion of success in FL, it must be contained in the notion that FL produces ideas about the future that exceed the framework of the present [1]. Arguably, this could produce foresight results to be fed into decision-making. This dimension helps actors develop or adapt their own strategies.

FL is constantly repeating itself in that capacity. It is a recursive bridge that links the anticipation in the present to the images of the future. Hence, FL is always in the making. No upper limit is ever met nor is any final equilibrium achieved. Thus, FL contains self-replicating loops that maintain and possibly accelerate the level and nature of being future literate.

As such, FL can be understood as recursive, referring to the cyclical nature of actions in which all procedures can be undertaken repeatedly until a specified condition is met. The logic and terminology of functional explanations, as clarified by Stinchcombe [25], may be relevant here. Sustained consequences that in turn function indirectly because of the behaviour or structures we are going to explain, we call $\mathrm{H}-$ a homeostatic variable. It tends to be stable in empirical reality, even if social forces try to change it. The behaviour or structure that has a (positive) causal effect on homeostasis is called S.

The causal relationship between $\mathrm{S}$ and $\mathrm{H}$ keeps $\mathrm{H}$ constant or varying between specified (homeostatic) boundaries. Other causal forces, stresses or difficulties that can disturb the balance of $\mathrm{H}$ or prevent it from occurring as usual, unless $\mathrm{S}$ compensates for this, we call $\mathrm{T}$ - the tension, which produces variations in $\mathrm{H}$. In addition, we find a causal process (e.g., development, competition, satisfaction, rewards from others, etc.) that allows those values of $\mathrm{S}$ that can restore and maintain $\mathrm{H}$ to be selected as functional alternatives and strengthened again.
$\mathrm{H}$ can denote $\mathrm{FL}$ and $\mathrm{S}$ the structures, technologies and behavioural patterns that constitute 'anticipation' selected because they influence FL actions, while $\mathrm{T}$ becomes different social schemes or behavioural outlets that can interfere with or limit the FL from arising. As the external tension $(\mathrm{T})$ increases, FL will not be maintained by itself. However, the higher the tension, the more the anticipative activity level in the structure will function to restore the FL.

If there is a causal link between anticipation (S) and FL $(\mathrm{H})$ such that $\mathrm{S}$ is selected or strengthened again if FL is maintained, then the various anticipative drivers found in the situation are more likely to maintain the FL. Moreover, if several structures (drivers) have the consequence of maintaining $\mathrm{FL}$, then it is possible that all of them are caused by a functional causal system. Formalized, the logic appears as in Fig. 1.

Overall, if we find many different behavioural patterns in the same or different groups, all of which have the same consequences, this suggests that the consequences are causally critical and the variations are random ([25], p. 99). This way of explaining functional causal processes can have many different variations and may be applied to many social phenomena (for example, different types of futures literacy), but the basic features will be the same in each case.

The effects of a given structure will next act as the cause of the structure. A persistent, recursive circle is established so that this pattern is maintained stably over time. Stability disturbances can occur, both through measures aimed directly at neutralizing the impact and through the creation of more effective alternatives to the structure.

Figure 1 shows that the links between $\mathrm{S}$ and $\mathrm{H}$ are mediated by social mechanisms (denoted by \pm ) that are not referred to as variable types. However, a complete functionalist explanation must include how this backward and forward process occurs. It is not enough to assume that it takes place; the dissemination mechanisms must be identified and analysed. This part of the functionalist explanation is often the weak point. Thus, the causal link between $\mathrm{S}$ and $\mathrm{H}$ may be obscured rather than revealed.

\section{Historicist functional explanations}

By adding a historical explanation to the understanding of FL, we can take this recursive logic a step further, while still placing $\mathrm{FL}$ as a homeostatic variable $(\mathrm{H})$ and anticipation as a structure (S) that causes FL. This will yield a model in which an effect created by causes at some previous period becomes a cause of that same effect in succeeding periods. This model makes it different from forecasting in that $\mathrm{H}$ is moderated by both internal $( \pm)$ and external $(\mathrm{T})$ forces. $\mathrm{H}$ prevails as such, but the 


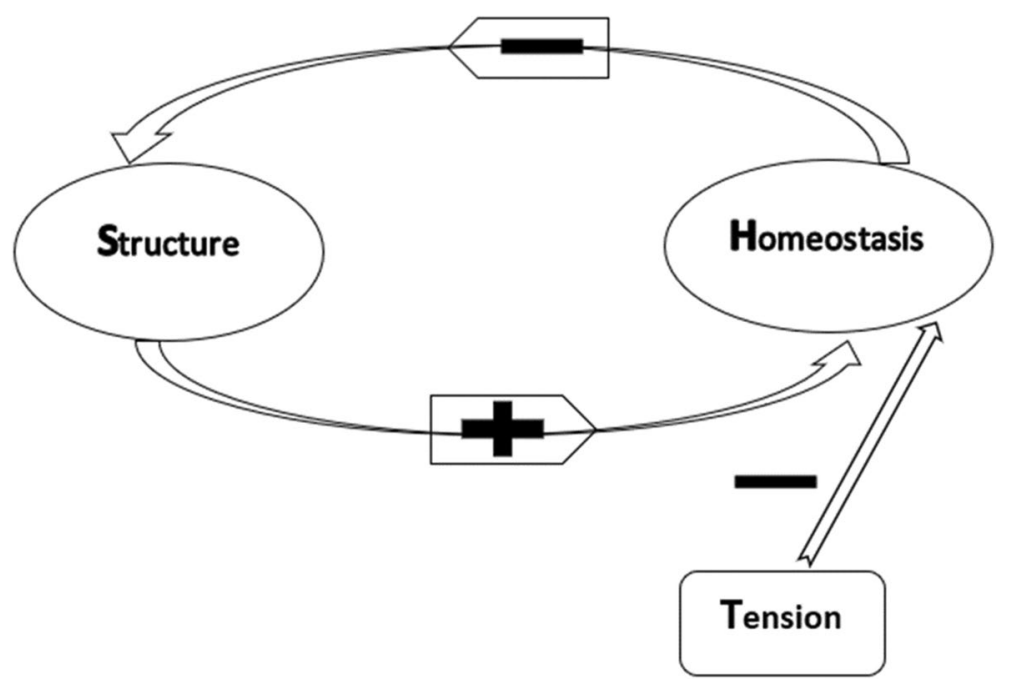

Fig. 1 Structure in a functional explanation

content of $\mathrm{H}$ is not the same as in the preceding period. Stinchcombe [25] calls this a historicist functional explanation, which can be applied to a phenomenon caused by a system of constant causes, and the pattern that occurs causes its own reproduction. From a purely sociological point of view, we are therefore aiming to explain two conditions: first, the special circumstances that make this pattern occur, and second, the general process by which the social pattern reproduces itself.

Assume also that there is something which we may call past literacy - that is, a capability of former times to envision and anticipate a future different from that experienced at that stage. Through processes such as learning, selecting, and planning, new ideas and powers grew, shaping society into something else, which we may call the present. This present and its literacy represents a functional alternative to the past and will, through its novel competence, capacity, and anticipation, influence the emerging futures literacy, as depicted in Fig. 2. This functional form of historicist explanation assumes a linear time concept and that there will always be some sort of literacy in the making of the social processes.

The model follows a historical axis of time: past, present, future. Historical evidence informs us about what has happened in the past but not about what could have occurred. Thus, 'one is not able to specify the uncertainty in the expectation on the basis of historical variations because the distribution of other possibilities is

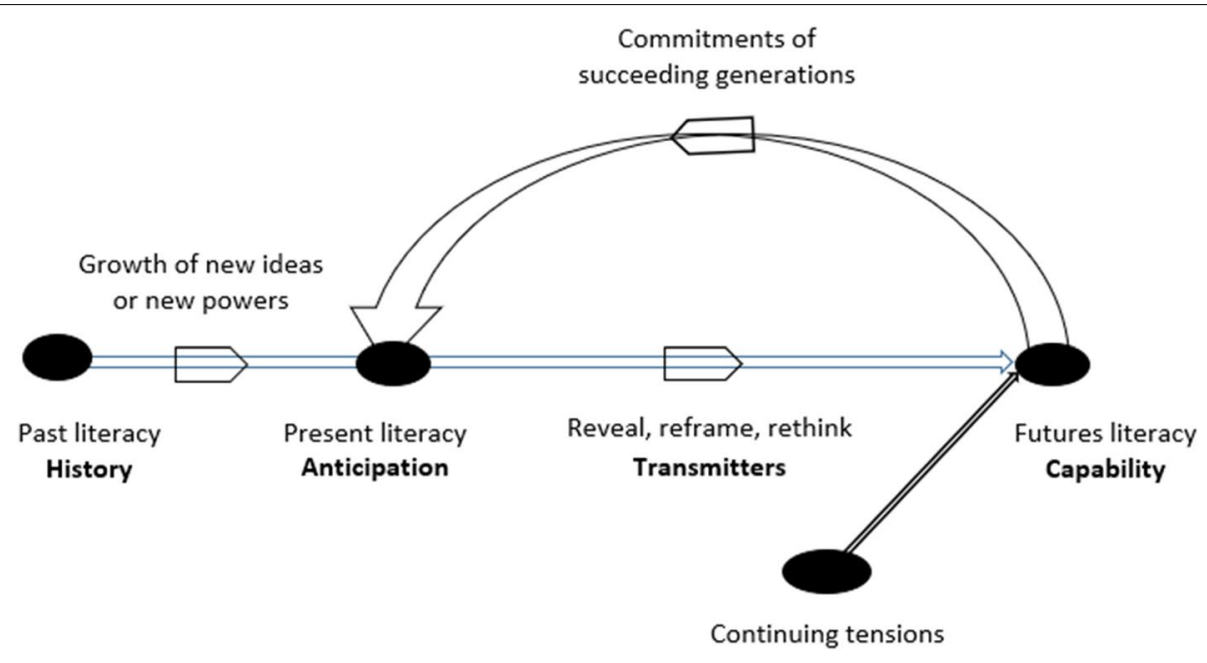

Fig. 2 The functional form of historicist explanations 
not "given" in reality' ([26], p. 21). Sense-making of past and present literacy is not sufficient to produce a futures literacy. Cognitive processes of anticipation must be included.

The anticipation embedded in the present literacy is stimulated and transferred by transmitters that increase the learning skills to use-the-future, thus establishing a certain level, capability, or proficiency of futures literacy. In such a way, a feedforward process [27] is the learning output from anticipating the future concerning the desired behaviour that the subject is encouraged to adopt. In purposeful activity, feedforward reasoning creates an expectation that the actor anticipates. When the expected literacy occurs, this provides confirmatory feedback. This feedback process of futures literacy is maintained, moderated, or strengthened by the commitments and actions of succeeding generations. Thus, in feedforward mode, the system's output (FL) can change without any reaction from an actor, while in feedback mode, any change in the $\mathrm{FL}$ will initiate a reaction of an actor.

When the actor has learned to activate the anticipation by the liberating transmittance signals (e.g., revealing, reframing, rethinking [1];) in its environment, the capability to-use-the-future may be loaded elsewhere in its environment, thus creating the recursive process of forward- and backward-feeding loops, as depicted in Figs. 1 and 2. They illustrate that the functional explanation assumes that FL implies both a feedforward and a feedback process in a continuous and recursive manner. FL is not a static capability with a prescribed level of proficiency. It is constantly expanding, and this learning takes time, so time must be part of the FL equation.

Let us illustrate this recursivity logic by using the case of the telephone. Formerly, a telephone was a corded device that (from 1876) allowed sounds to be transferred over some distance from one user to another. Making a telephone call required a novel, if low-level, proficiency. Presently, a telephone is something quite different. Mobile telephone technology was first introduced in the 1950s, but it did not spread until the GSM-net was developed in the 1990s (2G in 1992 corresponds to past literacy in Fig. 2). Gradually, the cell phone was accepted as portable (mobile) - something you could carry with you as opposed to house telephones fixed in a room. $2 \mathrm{G}$ technologies also enabled data services such as text messages, picture messages and multimedia messages. All text messages sent over $2 \mathrm{G}$ were digitally encrypted, allowing the transfer of data in such a way that only the intended receiver could receive and read it. The next $3-4 \mathrm{G}+$ technologies (1998-2020) increased the download speed and made possible a series of new functionalities, each requiring people to master new proficiencies. Increasingly, added applications have transformed the telephone into a functional alternative to many other technologies and behaviours, driven by imaginings of what the new mobile phone could be used for - ideas and applications reinforced by succeeding generations of mobile phone literate users (e.g., 3-4G+ corresponds to present literacy in Fig. 2). Cellular phone companies began deploying 5G worldwide in 2019. 5G (corresponding to futures literacy in Fig. 2) is designed to do a variety of things that presumably can transform our lives, including giving us faster download speeds, low latency and more capacity and connectivity for literally billions of devices - especially in the areas of virtual reality, internet of things and artificial intelligence.

Of course, external, continuing tensions arise; regulations, new framework conditions, market competition and succeeding versions of cell phone generations constantly emerge. Apparently, information literacy has no upper limit - it is ever-changing, and a cell phone literate will never be fully educated and proficient. Mackey and Jacobson (2014) reframe the many kinds of emerging information literacies (media, digital, ICT, visual literacy, etc.), as subsumed in the 'metaliteracy' concept. They claim that metaliteracy is a capability, rather than a set of competences, and contains critical thinking and collaboration within new digital environments. The concept parallels UNESCO's [28] claim that multifaceted media and information literacy is a core capability of lifelong learning. Metaliteracy is surely some kind of futures literacy, and it will prevail in the causal loop because of the commitments of succeeding generations of 'digi-natives'.

According to Stinchcombe [25], which functional alternatives are chosen amongst many is usually determined by historical events. And once a functional alternative is selected and established, it tends to remove the power of its original competitors or alternatives and thus recreate itself. This explanatory logic model applies to many different forms of futures literacy, including being able to explain both their historical origins and reproduction patterns.

These action and reaction forces will create such selfreplicating causal loops, causing the present literacy to change in such a way that it affects the next stage of futures literacy. Eventually, the mobile phone of today will be replaced by some functional alternative produced by novel anticipation in the present. It remains to be seen in the emergent present of what and in what form.

\section{Conclusion}

This article suggests three take-home messages. First, FL is a broad concept that encompasses all forms of produced future literacy, not exclusively what is produced in a particular Futures Literacy Laboratory. A stricter definition of FL and more comprehensive tests of the practice 
field of FL are needed to increase both the trustworthiness of FL as a scientific concept and its applicability in guiding institutional change.

Second, FL must be measurable to qualify as a proficiency, as we require from other forms of literacy (reading, writing, arithmetic, etc.) However, FL lacks measurable criteria. The core ideas embedded in the FL concept call for a criterial assessment of its characteristics and scientific validity.

Third, and this is the core message in this article, all FLs follow the same underlying logic - a recurring repercussion to the emergent present. As such, FL will replicate itself in a loop, however, the content of the FL will change accordingly.

Arguably, FL links to all three aspects of the Greek triangle $[2,3]$. Thinking about the future is the cognitive dimension of foresight. This implies being able to imagine possible futures and create a general awareness of trends and future issues by building scenarios, future images, technology assessments and different types of future studies. Discussing the future is the normative or value-based foresight dimension. It involves open discussion between different stakeholders, preferably in the form of panels, to create a common understanding of the actors' social mission, visions, and organization. Finally, shaping the future is the action-oriented or pragmatic dimension of foresight.

However, if FL is to be deemed a proficiency or a capability (as suggested by [1]), it must be possible to measure it. And measurement requires criteria against which a particular proficient achievement can be compared. FL has no such inherent characteristics, so it may be deemed 'a primitive term' - a concept encompassing some level of face validity, at best. Arguably, any image of a future, produced by means of any known foresight method will suffice as FL. To claim that FL must be produced by a particular FLL procedure is not reasonable because the FL definition (by [1]) does not specify any measurable criteria to be met.

The historicist functional logic attempts to explain phenomena according to their consequences, and the model illustrates that any kind of futures literacy and other foresight ideas about the future will be subject to this feedforward and feedback logic. The model also assumes that homeostasis $(\mathrm{H})$ is an empirically observable variable, not (only) a theoretically defined construct. To meet that requirement, futures literacy as a phenomenon must be observable and possible to measure in empirical terms - that is, the FL concept needs criteria to obtain scientific trustworthiness. Increasing the content validity of the FL concept calls for a stricter methodological approach, facilitating comparisons between different FL delivery platforms. Despite the lack of a best practice, the fundamental recursive logic sticks to most learning approaches that promotes futures literacy.

Arguably, it is a tall order to become 'futures literate', its syllabus encompasses all kind of foresight activities using foresight methodologies. Such proficiency requires being familiar with and practising a wide variety of foresight methods. As such, it calls for a multi-factor process linked to procedural approaches of creativity, evidence, interaction, and expertise (Popper, 2008). Debatably, futures literacy is not exclusively achieved in an FLL, as suggested by Miller [1]. It may very well be attained in a Causal Layered Analysis setting ([29], 2019) or in staging Postnormal methodologies [30], or in any other wellstructured Futures workshop designed to break existing paradigms of envisioning and operating the pathways to a preferred future.

\section{Author's contributions}

The author(s) read and approved the final manuscript.

\section{Competing interests}

The authors declare he has no competing interests.

Received: 31 March 2021 Accepted: 4 November 2021

Published online: 23 November 2021

\section{References}

1. Miller R (ed) (2018) Transforming the future: anticipation in the 21st century. Routledge, London

2. Godet M (1994) From anticipation to action: a handbook of strategic prospective. UNESCO Publishing, Paris

3. Godet M (2010) Future memories. Technol Forecasting Soc Change 77:1457-1463

4. Stordy P (2015) Taxonomy of literacies. J Doc 71(3):456-476. https://doi. org/https://doi.org/10.1108/JD-10-2013-0128. Accessed 14 July 2020

5. Gerring, J. (1999) What makes a concept good? A criterial framework for understanding concept formation in the social sciences. Polity, Vol. 31, No. 3 (Spring): 357-393

6. Mead GH (1932) The philosophy of the present, edited, with an introduction by a.E. Murphy. Open Court, La Salle, Illinois

7. Miller R (2006) From trends to futures literacy: reclaiming the future. The Centre for Strategic Education, Melbourne

8. Miller R (2007) Futures literacy: a hybrid strategic scenario method. Futures 39(4):341-362

9. Miller R (2011) Futures literacy - embracing complexity and using the future. Ethos 10:23-28

10. Miller R (2015) Learning, the future, and complexity. An essay on the emergence of futures literacy. Eur J Educ 50(4):513-523

11. Adam B (2004) Time. Polity Press, Cambridge, MA

12. Selin C (2008) The sociology of the future: tracing stories of technology and time. Sociol Compass 2(6):1878-1895. https://doi.org/10.1111/j.17519020.2008.00147.x Accessed 7 February 2019

13. Karlsen JE, Øverland EF, Karlsen H (2010) Sociological contributions to futures' theory building. Foresight 12(3):59-72

14. March JG (1995) The future, disposable organizations and the rigidities of imagination. Organization 2(3/4):427-440

15. Nordlund G (2012) Time-scales in futures research and forecasting. Futures 44:408-414

16. Rogoff B, Paradise R, Mejía Arauz R, Correa-Chavez M, Angelillo C (2003) Firsthand learning through intent participation. Annu Rev Psychol 54:175-203. https://doi.org/10.1146/annurev.psych.54.101601.145118.d 
17. SuddendorfT, Corballis MC (1997) Mental time travel and the evolution of the human mind. Genet Soc Gen Psychol Monogr 123:133-167

18. Suddendorf T, Corballis MC (2007) The evolution of foresight. What is mental time travel and is it unique to humans? Behavioral and brain sciences (prepress draft 2007)

19. Bell W (2002) A community of futurists and the state of the futures field. Futures 34(3/4):235-247

20. Weick KE, Sutcliffe KM (2001) Managing the unexpected: assuring high performance in an age of complexity. Jossey Bass, San Francisco

21. Tsoukas M, Hatch MJ (2001) Complex thinking, complex practice: the case for a narrative approach to organizational complexity. Hum Relat 54:979-1013

22. Cunha MP (2002) Time travelling: Organisational foresight as temporal reflexivity. Paper presented at the Probing the future conference, Glasgow, 11-13 July 2002

23. Louie AH (2010) Robert Rosen's anticipatory systems. Foresight 12(3):18-29

24. Merton RK (1957) Social theory and social structure. The Free Press, New York

25. Stinchcombe AL (1968) Constructing social theories. Harcourt, Brace \& World, New York
26. Leydesdorff $L$ (2005) Anticipatory systems and the processing of meaning: a simulation study inspired by Luhmann's theory of social systems. J Artif Soc Soc Simul 8(2). Paper 7 at http://jasss.soc.surrey.ac.uk/8/2/7.html. Accessed 13 July 2020

27. Logan RK (2015) Feedforward, I. a. Richards, cybernetics and Marshall McLuhan. Syst Connecting Catter Life Cult Technol 3(1):177-185 Available at http://openresearch.ocadu.ca/id/eprint/650/. Accessed 13 July 2020

28. UNESCO (2013) Media and information literacy: policy and strategy guidelines. UNESCO Publishing, Paris http://unesdoc.unesco.org/images/ 0022/002256/225606e.pdf. Accessed 13 July 2020

29. Inayatullah, S. (2008). Six pillars: futures thinking for transforming. Foresight, 10(1): 4-21, DOI: http://dx.doi.org/https://doi.org/10.1108/14636 680810855991

30. Sardar Z, Sweeney JA (2016) The three tomorrows of Postnormal times. Futures 75:1-13

\section{Publisher's Note}

Springer Nature remains neutral with regard to jurisdictional claims in published maps and institutional affiliations.

\section{Submit your manuscript to a SpringerOpen ${ }^{\odot}$ journal and benefit from:}

- Convenient online submission

- Rigorous peer review

- Open access: articles freely available online

- High visibility within the field

- Retaining the copyright to your article

Submit your next manuscript at $\gg$ springeropen.com 